\title{
Analysis of the fungal, archaeal and bacteriophage diversity in the human distal gut
}

\author{
Eric Brown, Emma Allen-Vercoe
}

\author{
This study was conducted under the supervision of Dr. Emma Allen-Vercoe, \\ Molecular and Cellular Biology, College of Biological Sciences \\ University of Guelph
}

\begin{abstract}
The composition and role of bacteria in the human gut has been studied intensely and is a burgeoning field of scientific research. However, there is a relative lack of research on other microorganisms which compose our gut flora such as bacteriophage, archaea and fungi. The aim of our study was to begin to fill this gap. The archaeal, fungal and bacteriophage diversity in the gut was analyzed using a PCR-DGGE fingerprinting method on fecal samples from 3 healthy donors. These samples were inoculated into chemostats and the microbes were grown in continuous culture to model the interactions of our flora in vitro. Norepinephrine was also added to the chemostats to test the microbial community's reaction to stress. Here we report that, relative to bacteria, fungal and archaeal diversity in the gut is low. The archaeal populations seemed stable over time varied depending on the individual. Fungal populations were more variable over time and changes in the community structure were observed after the addition of norepinephrine. DNA sequence analysis confirmed the presence of fungal species that are not yet cultured, yet are residents of the gut. Species of Podophage can also be detected as residents of the gut based on sequence analysis. It is clear that there is a core set of archaeal and fungal species living as residents in the gut. Bacteriophage are also present but their ecological role and effect on the microbial community in the gut is unknown.
\end{abstract}

$F^{2}$ rom the very first moments of birth, to our inevitable death, humans live in close association with the microbes that constantly surround us. There are a large number of bacteria, archaea, fungi and bacteriophage that make up what is referred to as our normal human flora or microbiota $[1,2]$. Over the past few years, the diversity, composition and role of the bacterial part of our flora has been studied intensely and is a burgeoning field of scientific research [2]. However, the roles of fungal, archaeal and bacteriophage communities in the human gut are not as well studied. For example, many of the previous surveys of fungal species in the human gut used culture-dependent approaches, which result in a culturebias since many gut organisms have been found to be refractory to anexic culture [3]. Recently, there have been some studies, using culture-independent approaches, confirming that archaeal, fungal and bacteriophage populations are an important part of our gut flora [3, 4, 5]. Yet there have been a very limited number of studies; and the roles of archaeal, phage and fungal flora in human health and disease are not well known to date.

The microbial ecology of the human gastrointestinal tract (GI tract) has significant clinical interest due to the key role the GI tract plays in digestion, nutrition and maintenance of host physiology [6]. It is estimated that the GI tract contains $70 \%$ of all microbes in the human body, making it an extremely complex ecosystem harbouring more than 100 trillion microorganisms [7]. That is about 10 times the number of human cells per individual [1], making us a walking ecosystem of prokaryotic cells, eukaryotic cells and the viruses or bacteriophage that infect them. Maintenance of a healthy GI tract is important, and there are diseases associated with an imbalance or altered state of gut microbiota collectively called inflammatory bowel disease (IBD). These diseases affect millions of people worldwide, giving an even greater importance to understanding the function and role of our gut microbiota.

To study the microbiota of the GI tract, our lab uses continuous culture vessels called chemostats to model the conditions of our gut (Figure 1). In this system, microbes that are refractory to anexic culture can be modelled in vitro.

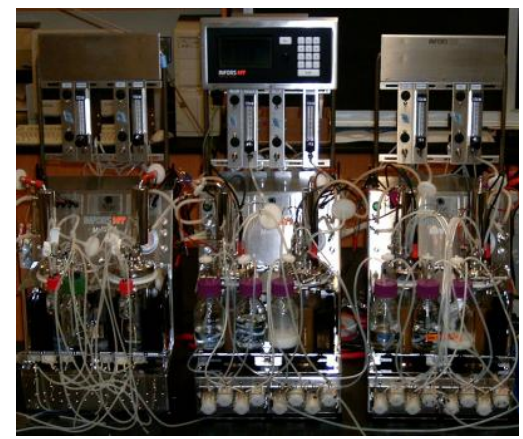

Figure 1 Picture of 3 chemostat vessels running on continuous culture in order to model conditions seen in the human gut 
There is evidence from our lab that the use of chemostats can support the growth of populations of bacterial species from feces. The central purpose of this study was to see if the vessels could also support growth of fungal, archaeal and bacteriophage species, and find out which species are represented in the GI tract flora of healthy donors. It is important to note that fecal samples do not represent the microbial communities found the entire GI tract, just the distal colon region. Preliminary studies show a high correlation between bacterial populations in a fecal sample when compared the population found in a chemostat run of up to 2 months. Chemostats also provide a good model to study the effects of exogenous stimuli on a complex microbial population. Recently, there has been a hypothesized link to how stress hormones may lead to a greater susceptibility of infection by our resident microbes [8]. To follow up on these studies, the stress hormone norepinephrine was added to the chemostat vessels, and changes were observed in bacterial community structure. Thus another reason for this study was to see what effects norepinephrine has on fungal, bacteriophage and archaeal community structure.

In this study, we assessed the bacteriophage, archaeal and fungal diversity and overall shape of communities in the intestines of healthy donors using PCR and denaturing gradient gel electrophoresis (DGGE) on the 16S rRNA, 18S rRNA genes and DNA polymerase genes of bacteriophage. Fungal DGG products were cut out, cloned and sequenced. The composition of archaeal and fungal species in each individual was then characterized by unweighted pair group method and arithmetic averages clustering algorithm (UPGMA) analysis of the DGGE banding patterns.

\section{RESULTS}

\section{PCR of 18S rRNA, 16S rRNA and Phage DNA Polymerase gene}

PCR was used on target genes to analyze the diversity of fungal, archaeal and bacteriophage species from fecal chemostat samples of healthy donors. For the first round of amplification, $18 \mathrm{~S}$ and 16S rRNA amplicons were examined by agarose gel electrophoresis to the correct molecular size of $\sim 1.6 \mathrm{kbp}$ for $18 \mathrm{~S}$ and $\sim 950 \mathrm{bp}$ for $16 \mathrm{~S}$ rRNA genes (see Figures $2 \mathrm{~A}$ and $3 \mathrm{~A}$ ). Target genes amplified well from the mixed sample of isolated chemostat DNA (which contained DNA from phage, fungal, archaeal and bacterial populations); however the amplified archaeal $16 \mathrm{~S}$ rRNA genes were not always visible on the gel. The second round of amplification yielded $\sim 1.5 \mathrm{kbp} 18 \mathrm{~S}$ rRNA amplicons and 400 bp 16S rRNA amplicons visible on a $0.8 \%$ agarose gel (Figures $2 \mathrm{~B}$ and $3 \mathrm{~B}$ ). The HECTOR and PARIS primers targeted the DNA polymerase gene of bacteriophage from the Podophage family, to amplify a 600 bp region of the gene. Isolated phage DNA and a mixed sample of chemostat DNA were used as templates for PCR (see Figure 4A and $\mathrm{B}$ respectively). When the reaction was electrophoresed on a $0.8 \%$ agarose gel, multiple products could be seen, indicating possible non-specific DNA amplification. Amplification of phage DNA direct from chemostat sample seemed to work well when using the PARIS primer set but not the HECTOR set (Figure 4A). Gradient PCR reaction with isolated phage DNA as a template, amplified 2 products of similar length (Figure 4B). Phage DNA was consistently amplified by the PARIS primer set, but with possible non-specific annealing of the primers.

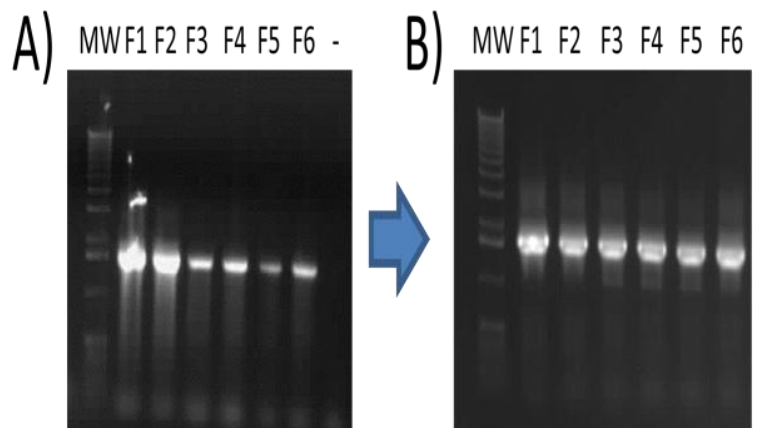

Figure 2 PCR products, using primer pair s NSO/EF3 (A), and NS1/FR1-GC (B) from Costa et al., 2005, yielding $1.6 \mathrm{kbp}$ amplicons were electrophoresed on a $0.8 \%$ agarose gel. Each reaction mixture in lanes F1-F6 consisted of 25 ng DNA template, DNA Pol. Buffer (NEB), $0.2 \mathrm{mM}$ dNTPs, $0.2 \mu \mathrm{M}$ each primer and 5U Taq DNA polymerase. After $8 \mathrm{~min}$ of denaturation at $94^{\circ} \mathrm{C}, 30$ cycles of $30 \mathrm{sec}$ at $94^{\circ} \mathrm{C}, 45 \mathrm{sec}$ at $48^{\circ} \mathrm{C}$ and $3 \mathrm{~min}$ at $72^{\circ} \mathrm{C}$ were performed on each reaction, followed by a $10 \mathrm{~min}$ extension step at $72^{\circ} \mathrm{C}$. The resulting PCR product was approximately $1 \mathrm{~kb}$. Molecular size markers are as indicated on the MW lane.

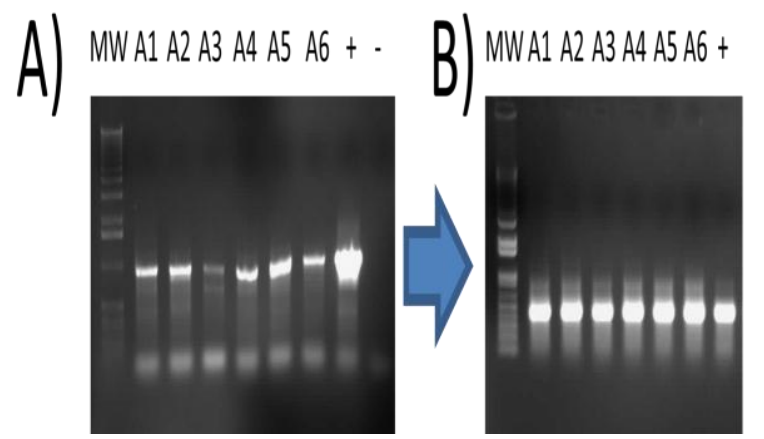

Figure 3 PCR products using primer pairs 21F/958R (A), and Parch519-Arch915-GC (B) from Vissers et al., 2009, yielding 400 bp amplicons (lanes A1-A6) were electrophoresed on an $0.8 \%$ agarose gel. Reaction mixtures analogous to fungal 18S PCR. After 2 min of denaturation at $94^{\circ} \mathrm{C}, 30$ cycles of $1 \mathrm{~min}$ at $94^{\circ} \mathrm{C}, 30 \mathrm{sec}$ at $57^{\circ} \mathrm{C}$ and $1 \mathrm{~min}$ at $72^{\circ} \mathrm{C}$ were performed on each reaction, followed by a $5 \mathrm{~min}$ extension step at $72^{\circ} \mathrm{C}$. The positive control (lane + ) indicated amplification of archaeal $16 \mathrm{~S}$ rRNA to the correct molecular weight. 


\section{MW P1 P2 P3 P4 P5 P6}

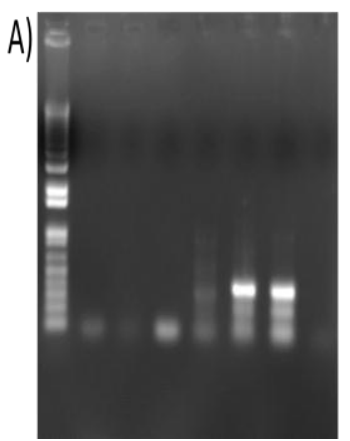

Figure 4 PCR products using primer sets HECTOR and PARIS from Breitbart et al., 2004, on maxwell prepped DNA (A), and isolated phage DNA (B) were electrophoresed on an $0.8 \%$ agarose gel. In Gel A, inoculum samples from feces of a healthy donor were loaded in lanes P1 and P4, samples from day 36 in the chemostat were loaded in lanes P2 and P5 and samples from day 48 in the chemostat were loaded in lanes P3 and P6. Lanes P1-P5 in gel B were inoculums from donor 2. Each reaction mixture consisted of 25ng DNA template, DNA Pol. Buffer (NEB), $0.2 \mathrm{mM}$ dNTPs, 1 $\mathrm{mM} \mathrm{MgCl} 2,0.2 \mu \mathrm{M}$ each primer and $5 \mathrm{U}$ Taq DNA polymerase. After $5 \mathrm{~min}$ of denaturation at $94^{\circ} \mathrm{C}, 35$ cycles of $1 \mathrm{~min}$ at $94^{\circ} \mathrm{C}, 1 \mathrm{~min}$ at $52^{\circ} \mathrm{C}$ (for $\mathrm{A}$ ) and $1 \mathrm{~min}$ at $50-57^{\circ} \mathrm{C}$ (for B) and $1 \mathrm{~min}$ at $72^{\circ} \mathrm{C}$ were performed on each reaction, followed by a 10 min extension step at $72^{\circ} \mathrm{C}$.

\section{Fungal DGGE Pattern Analysis}

The fungal community in the human distal gut was profiled by performing DGGE analysis on amplified $18 \mathrm{~S}$ rRNA genes (Figure 5). This resulted in DGGE profiles of 3 healthy donors (D2, D3 and D4) from fecal sample inoculums and across different time points of a chemostat run (Figure 5A). There were 5 prominent products found in all 12 samples (Figure 5A) and some that were widely distributed and found in more than half the samples. A DGGE profile of the fungal population in fecal chemostat samples from a single healthy donor (D2) across different time points revealed a relatively stable fungal population (Figure 5B). Six prominent products were found in all 6 samples, but over time in the chemostat runs, the amount of products observed tended to increase over time.

To analyze the DGGE profiles of the fungal communities in the human distal gut more clearly, the profiles were subjected to UPGMA cluster analysis (Figure 5). The different lanes were compared numerically with respect to the entire spectra of products seen by calculating the Dice correlation coefficients (Table 1). When these coefficients equalled 100 , this indicated that the banding pattern of the two respective lanes was equally distributed, and it could be said that they are $100 \%$ similar. The 12 fungal DGGE profiles across 3 different donors and different chemostat time points were between $43 \%$ and $94 \%$ similar with an average similarity value of $75 \%$. Across a single

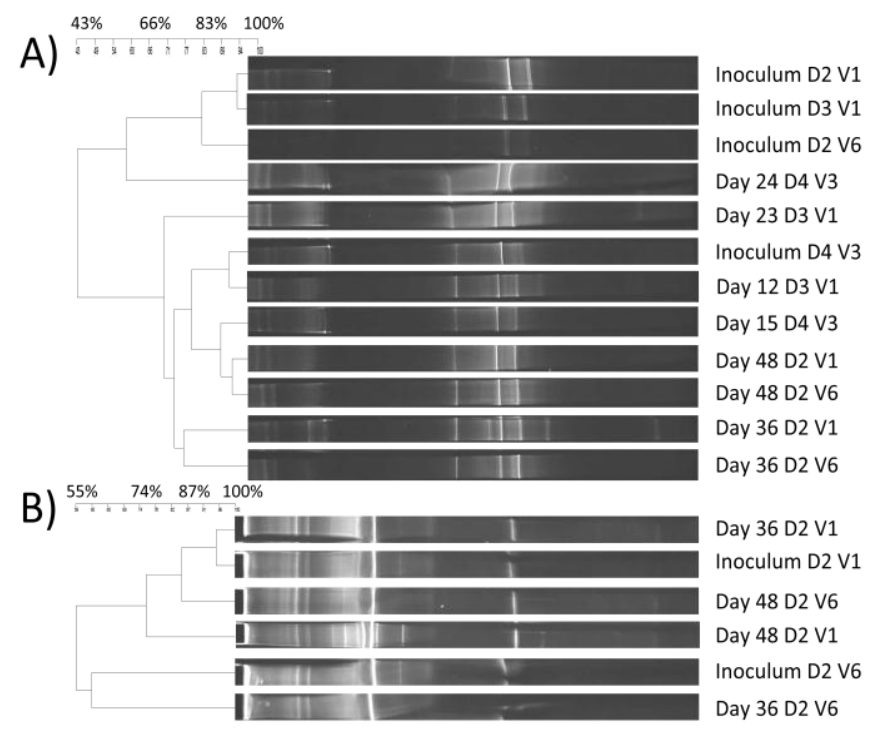

F1 F2 F3 F4 F5F6 F7 F8 F9 F10F11F12

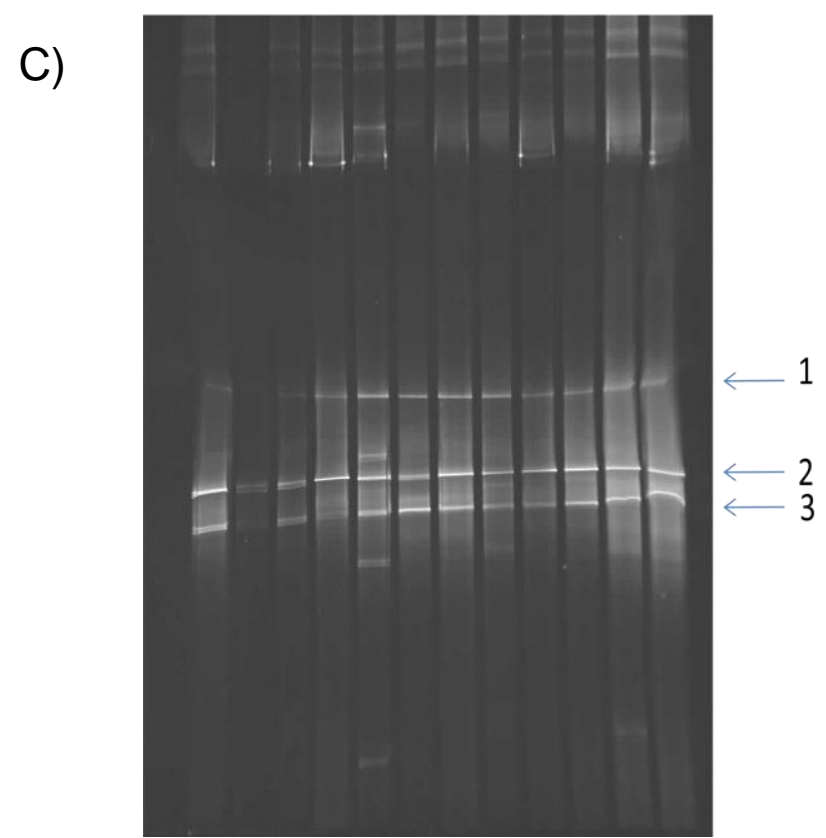

Figure 5 DGGE analysis of the fungal community in the human distal guts of healthy donors. Dendrogams constructed using Dice correlations and the UPGMA clustering method on the DGGE banding patterns from three different donors (D2, D3 and D4), from different chemostat vessels (V1, V3 V6) at different time points (A). Differences in the DGGE banding pattern over time from a single donor (D2) were also compared (B). Norepinephrine was added to the vessels on Day 37. The cluster analysis on DGGE gel $C$ is shown by DGGE gel $A$. Three bands were removed for sequencing from $\mathrm{D} 2$ and $\mathrm{D} 3$ as shown by the arrows (C). DGGE gels contained a denaturing gradient of 18 to $38 \%$ denaturants and $6 \%$ acrylamide. Electrophoresis was performed in $1 \mathrm{X}$ TAE buffer at $58^{\circ} \mathrm{C}$ and voltage of $180 \mathrm{~V}$ for 18 hours. Dendrograms were produced by SynGene software. 
donor over different chemostat time points, the profiles were between $55 \%$ and $95 \%$ similar with an average similarity value of $73 \%$ (Figure 5B). The inoculum samples from donor 2 and 3 were clustered together, representing 3 of the 4 inoculum samples tested, and formed a separate branch of the clustering tree along with a sample from day 24 from donor 4 (Figure 5A). DGGE profiles of samples from donor 2 after 36 days in the chemostat were clustered together and samples from donor 2 after the addition of norepinephrine (day 48) were also clustered together. However, in the DGGE profiles of donor 2 in Figure 5B, clustering of certain time points was not observed although day 48 samples were both outliers to the rest.

\section{Archaeal DGGE Pattern Analysis}

The archaeal community in the human distal gut was also profiled using DGGE analysis, on the amplified 16S rRNA genes (Figure 6). This resulted in DGGE profiles of 2 healthy donors (D3 and D4) from fecal matter inoculums and across 2 different time points in the chemostat run from each donor. There were 7 prominent products found in all 6 samples, with little change in banding pattern over time or between donors (Figure 6). To back this up, the DGGE profiles were clustered using UPGMA and different lanes were compared numerically by calculating the Dice correlation coefficients analogous to the fungal clustering method. The archaeal DGGE profiles were between $83 \%$ and $96 \%$ similar, with an average similarity value of $91 \%$ across different donors and chemostat time points (Figure 6). The 3 DGGE profiles from each donor were also clustered together, and were approximately $92 \%$ similar for donor 3 and $88 \%$ similar for donor 4 (Figure 6).

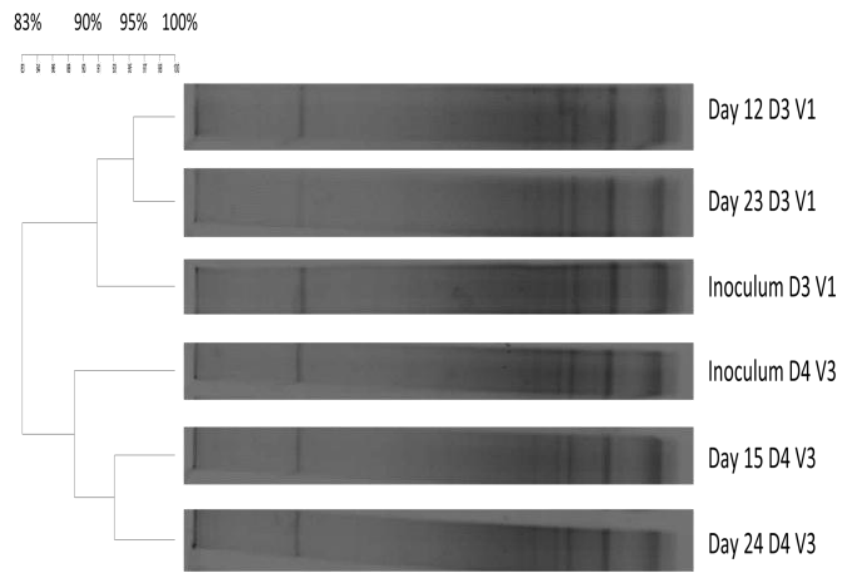

Figure 6 Dendrogam was constructed using Dice correlations and the UPGMA clustering method on the DGGE banding patterns from two different donors (D3 and D4), from different chemostat vessels (V1 and V3) at different time points. DGGE gels contained a denaturing gradient of 30 to $55 \%$ denaturants and $6 \%$ acrylamide. Electrophoresis was performed in $1 \mathrm{X}$ TAE buffer at $60^{\circ} \mathrm{C}$ and voltage of $120 \mathrm{~V}$ for 5 hours. Dendrograms were produced by SynGene software.
Cloning and Sequence analysis of Fungal DGGE Products

Three products from two different donors (D2 and D3) were excised from the DGGE gel (Figure 5C), for a total of 6 products. The 3 chosen products from each donor ran migrated the same length down the gel so theoretically represented the same species. When the transformations were plated on LB/kan/X-gal/IPTG plates, 3 of the 6 cloning reactions were successful represented by, white colonies. The 3 ligations that worked were product 2 from D3 and D2 and product 3 from D2 (Figure 5C). These 3 plasmids with ligated DNA from the $18 \mathrm{~S}$ rRNA region were successfully sequenced, and their sequence was analyzed using BLAST (Table 1). Product B from each donor (D2B and D3B) turned out to be from an uncultured fungal species, while product $\mathrm{C}$ from donor 2 (D2C) showed similarity to a gene found in Bacteroides fragilis.

\section{Cloning and Sequence analysis of Phage PCR Products} PCR product of amplified phage from Lane P4 (Figure 4A) and Lane P6 (Figure 4B) were ligated successfully and transformed into $E$. coli $\mathrm{DH} 5 \alpha$ cells as indicated by the presence of white-colonies on the LB/kan/X-gal/IPTG plates. Three colonies were chosen from each plate (P4E1-E3 and P61-63) and the resulting plasmids were sent for sequencing. The sequencing reaction did not work for clones P62 and P63, however the rest of the clones were sequenced successfully (Table 1). All four sequences were analyzed using BLAST and all found to be most similar to an uncultured Podophage species from the previous Breitbart et al., 2004 study (Table 1). The difference was these ligated products were only $\sim 50 \mathrm{bp}$ long, while the actual products in the database there were similar to were $\sim 600$ bp long. However most showed $100 \%$ sequence identity.

\section{DISCUSSION}

\section{PCR and Primer Design}

A dearth of information exists on the population structure and diversity of fungal, archaeal and bacteriophage species in the GI tract of humans, and the primary aim of this study was to use a PCR-DGGE method to address this concern. The primers used in this study were adopted from previously published studies, but in this case we use them on chemostat samples of fecal matter. In those studies, they observed a nested PCR approach worked well to amplify fungal and archaeal DNA templates which have a low population density in a mixed chemostat sample compared to bacterial and phage DNA. Results from this study confirm that, with good, clean amplicons observed in final amplification step of the expected sequence in each case (Figures 2 and 3). It is important to note that two previous studies [3, 4] reported that the protozoan Blastocystis spp. is a major component in the micro-eukaryotic community in out gut, and while the goal of this study is to assess fungal diversity, the $18 \mathrm{~S}$ rRNA primers may pick up $18 \mathrm{~S}$ genes from other micro-eukaryotes. The bacteriophage primers 
were specifically for the Podophage family, as no gene target exists that is conserved through all phage species. The family Podophage are characterized as T7-like lytic phages, and a previous study demonstrated them to a significant part of the human intestinal virome [9].

\section{Fungal Diversity in the Human Distal Gut}

The human GI tract is a complex environment populated by bacterial, archaeal and fungal species [1]. The density of the microbial community in this environment is higher than in any other ecosystem on earth, where there exists upwards of approximately 1000 bacterial species [2, 7]. However based on our DGGE data, the diversity of fungal species in the human GI tract seems to be low compared to prokaryotes (Figure 5). There are 5 conserved products across the DGGE profiles and a total of approximately 15 distinct products (Figure 5C). This lack of diversity is backed up by two previous studies which showed only 3 distinct products per individual [3] and 8-10 products per individual [4]. In these studies, Scanlan et al. reported some similarity (43\%) between the fungal profiles of different donors, while Nam et al., reported $31 \%$ similarity to the fungal communities from different donors. Here we report that fungal flora between our 3 healthy donors is fairly similar, and major species seem stable over time in the chemostat. This indicated that the chemostat can retain fungal communities seen in fecal matter (inoculums sample). Cluster analysis reports an average of $75 \%$ similarity between all fungal profiles from different donors and time points and $73 \%$ similarity of the fungal profile from the same donor but across different time points (Figure 5A and B). This is much higher than previously reported. Fungal diversity seems to be as dependent on time point in the chemostat run, as much as which donor they we isolated from, although it is hard to make conclusions with a donor sample size of 3. Interestingly, fungal DGGE profiles from chemostat profiles in steady state (day 36) and after norepinephrine was added (day 48) were clustered together (Figure 5A). There are also visible changes in the banding patterns. While the dominant, constant species are still detectable, products appear and disappear indicating a possible shift in the fungal population. Most of the inoculums samples are clustered together and these samples seem to have less diversity of products compared to DGGE profiles from later in the run. More studies are needed on different healthy donors and possibly from donors with an IBD. Three DGGE products were cloned and sequenced successfully from donor 2 at day 36 (2 bands) and donor 3 at day 23 (Table 1). Two of the sequences turned out to be from an uncultured fungal species, while the other amplified the carbamoyl-phosphate synthase gene from Bacillus fragilis a common prokaryotic inhabitant of the GI tract. More cloning and sequence analysis is needed but this indicated that the primers may be binding non-specifically in some cases.
Table 1 Sequence data collected from DGGE Bands

\begin{tabular}{|c|c|c|c|c|c|}
\hline Clone & $\begin{array}{c}\text { Nearest } \\
\text { Sequence }\end{array}$ & Identity & E-Value & Score & Kingdom \\
\hline D2B & $\begin{array}{l}\text { Uncultured } \\
\text { fungus clone } \\
\text { WD4-32 } \\
18 \mathrm{~S} \\
\text { ribosomal } \\
\text { RNA gene }\end{array}$ & $100 \%$ & $1 \mathrm{e}-178$ & 634 & Fungi \\
\hline D3B & $\begin{array}{l}\text { Carbamoyl- } \\
\text { phosphate } \\
\text { synthase } \\
\text { from } \\
\text { Bacteroides } \\
\text { fragilis }\end{array}$ & $98 \%$ & $1 \mathrm{e}-110$ & 410 & Bacteria \\
\hline D2C & $\begin{array}{l}\text { Uncultured } \\
\text { fungus } \\
\text { isolate } \\
\text { DGGE gel } \\
\text { band } 218 \mathrm{~S} \\
\text { ribosomal } \\
\text { RNA gene }\end{array}$ & $100 \%$ & $1 e-139$ & 510 & Fungi \\
\hline P4E1 & $\begin{array}{l}\text { Uncultured } \\
\text { T7-like } \\
\text { podovirus } \\
\text { clone } 49 \\
\text { DNA } \\
\text { polymerase } \\
\text { gene }\end{array}$ & $100 \%$ & 0.70 & 41 & $\begin{array}{c}\text { Bacterio } \\
\text { phage }\end{array}$ \\
\hline P4E2 & $\begin{array}{l}\text { Uncultured } \\
\text { T7-like } \\
\text { podovirus } \\
\text { clone } 41 \\
\text { DNA } \\
\text { polymerase } \\
\text { gene }\end{array}$ & $100 \%$ & 0.81 & 40 & $\begin{array}{c}\text { Bacterio } \\
\text { phage }\end{array}$ \\
\hline P4E3 & $\begin{array}{l}\text { Uncultured } \\
\text { T7-like } \\
\text { podovirus } \\
\text { clone } 36 \\
\text { DNA } \\
\text { polymerase } \\
\text { gene }\end{array}$ & $100 \%$ & 1.3 & 38 & $\begin{array}{c}\text { Bacterio } \\
\text { phage }\end{array}$ \\
\hline P61 & $\begin{array}{l}\text { Uncultured } \\
\text { T7-like } \\
\text { podovirus } \\
\text { clone } 44 \\
\text { DNA } \\
\text { polymerase } \\
\text { gene }\end{array}$ & $100 \%$ & 0.84 & 40 & $\begin{array}{c}\text { Bacterio } \\
\text { phage }\end{array}$ \\
\hline
\end{tabular}




\section{Archaeal Diversity in the Human Distal Gut}

Previous studies indicate that each individual possesses a distinct population of archaea in their gut and with methanogens being the predominate archaeal species found in the human distal gut [4]. Our DGGE profiles show 6 distinct products conserved across 2 donors at different chemostat time points (Figure 6). Overall the archaeal community is stable over time, with greater than $88 \%$ similarity between the 3 DGGE profiles of each donor over time in the chemostat (Figure 6). The 3 DGGE profiles from donor 3 were clustered together and subsequently the DGGE profiles of donor 4 were all clustered together with an average similarity value of $91 \%$. This supports the fact that each individual has its own unique set of archaeal flora, but with high similarity in species content. The chemostat vessels seem to retain the archaeal populations well from the original inoculums sample. Given this, the two postinoculum chemostat samples (day 12 and 23 for donor 3 and day 15 and 24 for donor 4) were each clustered together (Figure 5). The inoculums samples were outliers, indicating slight some change over time. More DGGE analysis needs to be carried out to confirm this.

\section{Podophage in the Human Distal Gut}

Based on the sequencing data, the PARIS primers successfully amplified Podophage DNA. Also, they amplified similar sequences from an isolated phage DNA sample (P61) as well as from a mixed sample of bacterial, fungal and archaeal DNA. This is a good sign, however the length of the amplicons are much shorter than predicted by the primers and in the paper Breitbart et al., 2004. This could be because the primers amplified many parts of this DNA polymerase gene sequence, yet only the shortest bands ligated into the vector since shorter DNA bands tend to ligate at higher efficiencies. Also the e-values are low, yet this also may be because of the short sequence relative to the hit found on BLAST, and shows the novelty of the sequence. Future studies will be directed towards separating the bacteriophage DNA sequences using DGGE to get an overall community profile. Subsequent products could then be sent for sequencing.

\section{Conclusions and Future Directions}

In summary, in this study, we began to characterize the overall archaeal, fungal and bacteriophage diversity in the human distal gut using a molecular PCR-DGGE method. Clustering analysis of the DGGE band patterns revealed that the archaeal communities among individuals are much more similar than the fungal community. Also, fungal diversity is low and seemingly more variable between hosts and depending on the time point of sample collection. There were definite changes in the population of fungal species in chemostat samples observed over time, and after addition of norepinephrine. Yet, there is some stability in our fungal diversity over time indicated by a presence of six identical products in each profile. Therefore there seems to be a core set of archaeal and fungal species living as residents in our gut. It is also clear that there are bacteriophages who reside in our gut, and their effect on the global population of microbes there is relatively unknown. There are Podophage that can be found in our gut, and how many of them are there as well as the significance of their functioning role in the ecosystem still needs to be answered.

This study is still in its infancy, and more DGGE analysis needs to be done to confirm findings. All visible products will be sequenced to provide a better understanding of which species of fungus and archaea reside in our distal gut. The gut flora of IBD patients can also be studied to come to grips with how not only the bacteria are altered during these diseases but also our fungal, and archaeal flora along with bacteriophage.

\section{METHODS}

\section{Chemostat Sample Collection and Extraction of DNA}

The DNA used in this study was isolated from different time points in chemostat runs with fecal samples from healthy donors in each chemostat vessel (Figure 1). All DNA samples were extracted by Julie McDonald using a beadbeating method, removing the inhibitors using a kit (Omega E.Z.N.A. stool kit), and adding the resulting supernatant to a Maxwell kit.

\section{Phage DNA Isolation}

Approximately $2 \mathrm{~mL}$ of a chemostat sample was collected, containing fecal matter from a healthy donor, and mixed with a $4 \mathrm{X}$ volume of Phage Buffer $(100 \mathrm{mM} \mathrm{MgCl} 2,50 \mathrm{mM}$ $\mathrm{NaCl}, 50 \mathrm{mM}$ Tris-HCl $\mathrm{pH}$ 7.5). The mixture was shaken vigorously to dislodge phage particles from particulate matter and filtered with a $0.2 \mu \mathrm{m}$ Nitex filter. The filtrate was treated with $1 \mu \mathrm{L}$ of $10 \mathrm{U} / \mu \mathrm{L}$ DNase for $30 \mathrm{~min}$ at room temperature. The reaction mixture was heated for $20 \mathrm{~min}$ at $60^{\circ} \mathrm{C}$ to inhibit the enzyme. The phage particles were lysed and the DNA was extracted following a previously published protocol [10].

\section{PCR Amplification}

The extracted DNA from each chemostat sample was amplified by PCR with different primer sets for each target gene (see Table 2), followed by separation of the PCR products using Denaturing Gel Gradient Electrophoresis (DGGE). Nested PCR amplification was used to analyze the fungal and archaeal diversity. PCR amplification of archaeal 16S rRNA genes was performed using the arch21F-958R primer set [11] for the first amplication step, followed by the Parch519-915 [12] for the second amplification step, as described previously [13]. PCR amplification of fungal $18 \mathrm{~S}$ rRNA genes was performed using the fungalaNSO-EF3 primer set [14] for the first amplification step and the fungalbNS1-FR1 primer set [15] for the second amplification step as described previously [16]. Each primer used in the second amplification step had a 40 bp GC clamp for DGGE 
Table 2 PCR primers used in this study

\begin{tabular}{|c|c|c|}
\hline & Name & Sequence $\left(5^{\prime}-3^{\prime}\right)$ \\
\hline $\begin{array}{c}\text { Fungal- } \\
\text { specific } \\
\text { primers } \\
\text { 18S rRNA } \\
\text { gene } \\
\text { amplification }\end{array}$ & $\begin{array}{l}\text { fungalaNSO } \\
\text { fungalaEF3 } \\
\text { fungalbNS1 } \\
\text { fungalbFR1 }\end{array}$ & $\begin{array}{c}\text { TACCTGGTTGATCCTGCC } \\
\text { TCCTCTAAATGACCAAGTTTG } \\
\text { GTAGTCATATGCTTGTCTC } \\
\text { *AICCATTCAATCGGTAIT }\end{array}$ \\
\hline $\begin{array}{c}\text { Archaeal- } \\
\text { specific } \\
\text { primers } \\
\text { 16S rRNA } \\
\text { gene } \\
\text { amplification }\end{array}$ & $\begin{array}{l}\text { 21FArch } \\
\text { 958RArch } \\
\text { Parch519 } \\
\text { Arch915 }\end{array}$ & $\begin{array}{c}\text { TTCCGGTTGATCCYGCCGGA } \\
\text { YCCGGCGTTGAMTCCAATT } \\
\text { CAGCCGCCGCGGTAA } \\
* * \text { GTGCTCCCCCGCCAATTCCT }\end{array}$ \\
\hline $\begin{array}{l}\text { Phage- } \\
\text { specific } \\
\text { primers } \\
\text { DNA } \\
\text { polymerase } \\
\text { amplification }\end{array}$ & $\begin{array}{l}\text { HECTORf } \\
\text { HECTORr } \\
\text { PARISf } \\
\text { PARISr }\end{array}$ & $\begin{array}{l}\text { GCAAGCAAGTTTACTGTGG } \\
\text { CGAGAGATACACCAACGAA } \\
\text { ATACTACACGCTACTCTGG } \\
\text { CACTGGCAAGAGGAGTTAT }\end{array}$ \\
\hline
\end{tabular}

*A 40bp long GC-clamp (5'-CCC CCG CCG CGC GCG GCG GGC GGG GCG GGG GCA CGG GCC G-3') was attached to the end of the primer fungalbFR1 to prevent the complete melting of the PCR product during DGGE.

${ }^{* *} A$ 40bp long GC-clamp (5'-CGC CCG CCG CGC CCC GCG CCC GGC CCG CCG CCC CCG CCC C-3') was attached to the end of the primer Arch915 to prevent the complete melting of the PCR product

analysis. For amplification of phage DNA, primers PARIS and HECTOR were designed to amplify a specific region of the phage DNA polymerase gene [9] from the polymerases of phage from the family of Podophage (see Table 2). The reaction mixtures for this amplification consisted of $\sim 25 \mathrm{ng}$ DNA template, DNA Pol. Buffer (NEB), $0.2 \mathrm{mM}$ dNTPs, 1 $\mathrm{mM} \mathrm{MgCl}_{2}, 0.2 \mu \mathrm{M}$ of each primer and 5U Taq DNA polymerase. The reaction mixtures for the $18 \mathrm{~S}$ and $16 \mathrm{~S}$ rRNA PCR consisted of $\sim 25$ ng DNA template, DNA Pol. Buffer (NEB), $0.2 \mathrm{mM}$ dNTPs, $0.2 \mu \mathrm{M}$ of each primer and 5U Taq DNA polymerase. Fungal PCRs were cycled with 8 min of denaturation at $94^{\circ} \mathrm{C}, 30$ cycles of $30 \mathrm{sec}$ at $94^{\circ} \mathrm{C}, 45$ sec at $48^{\circ} \mathrm{C}$ and $3 \mathrm{~min}$ at $72^{\circ} \mathrm{C}$ followed by a $10 \mathrm{~min}$ extension step at $72^{\circ} \mathrm{C}$. Archaeal PCRs were cycled with 2 min of denaturation at $94^{\circ} \mathrm{C}, 30$ cycles of $1 \mathrm{~min}$ at $94^{\circ} \mathrm{C}, 30$ sec at $57^{\circ} \mathrm{C}$ and $1 \mathrm{~min}$ at $72^{\circ} \mathrm{C}$, followed by a $5 \mathrm{~min}$ extension step at $72^{\circ} \mathrm{C}$. Bacteriophage PCRs were cycled with $5 \mathrm{~min}$ of denaturation at $94^{\circ} \mathrm{C}, 30$ cycles of $1 \mathrm{~min}$ at $94^{\circ} \mathrm{C}, 1 \mathrm{~min}$ at $52^{\circ} \mathrm{C}$ and $1 \mathrm{~min}$ at $72^{\circ} \mathrm{C}$, followed by a 10 min extension step at $72^{\circ} \mathrm{C}$.

\section{DGGE Analysis}

Resulting PCR products were separated by DGGE using electrophoresis apparatus from Bio-Rad Laboratories, USA. A volume of $30 \mu \mathrm{L}$ of each PCR product was loaded on a $6 \%$ acrylamide gel with a denaturing gradient of 18 to $38 \%$ for fungal DNA and 30 to $55 \%$ for archaeal DNA in a running buffer of $1 \mathrm{X}$ Tris-acetate-EDTA. The denaturing agents used in the gel were urea and formamide. The DGGE was electrophoresed for 18 hours at $58^{\circ} \mathrm{C}, 180 \mathrm{~V}$ for fungal DNA and 5 hours at $60^{\circ} \mathrm{C}, 120 \mathrm{~V}$ for archaeal DNA. After electrophoresis, the gels were stained using ethidium bromide and photographed under UV transillumination. The DGGE profiles were analyzed using cluster analysis (Gene Tools by SynGene) and the lanes were normalized in order to compensate for differences in the migration distance of the DNA in each lane. Dendograms were computed (Gene Tools by SynGene) using the DICE similarity coefficient and unweighted pair group method and arithmetic averages clustering algorithm (UPGMA). The average similarity value was calculated by adding up all similarities between gels and dividing by the total.

\section{DGGE Band Excision, Cloning and Sequence analysis of Fungal and Bacteiophage species}

Sterile blades were used to excise products from the DGGE gels, which were then mixed with $50 \mu \mathrm{l}$ of TE buffer and incubated overnight at $4^{\circ} \mathrm{C}$. Resulting DNA was cloned into the pCR2.1 TOPO cloning vector using a TOPO cloning kit (Invitrogen, USA). PCR product for phage DNA was also cloned this way. The ligation reaction was transformed into E. coli $\mathrm{DH} 5 \alpha$ cells and plated on LB/kanamycin/X-gal/IPTG plates. White colonies were selected and grown in $5 \mathrm{~mL}$ of LB broth. The plasmid was mini-prepped from $E$. coli using a plasmid mini-prep kit (Qiagen, USA) and eluted in $50 \mu \mathrm{L}$ distilled water. Concentration of the plasmid DNA was checked using a nanospectrometer and sent to Bio-Basic for sequencing. The sequence was then analyzed using BLAST, on the NCBI database.

\section{ACKNOWLEDGEMENTS}

I would like to thank Dr. Emma Allen-Vercoe for the advice on the project and the opportunity to carry out this research in her laboratory. I would also like to express my gratitude to Michelle Daigneault, Chris Ambrose, Mike Toh, Jackie Strauss, Vadium Junea and Julie McDonald and the rest of the Allen-Vercoe lab for their advice assistance and support. Further thanks to Julie McDonald for providing the chemostat samples used in this study. I would also like to thank CIHR for the funding of this research.

\section{REFERENCES}

1. Ley R, Peterson D, Gordon J. 2006. Ecological and evolutionary forces shaping microbial diversity in the human intestine. Cell 124:837-848.

2. Sekirov I, Russel S, Caetano M, Finlay BB. 2010. Gut Microbiota in Health and Disease. Physiol Rev 90:859904. 
3. Scanlan PD, Marchesi JR. 2008. Micro-eukaryotic diversity of the human distal gut microbiota: qualitative assessment using culture-dependent and independent analysis of faeces. ISME 2:1183-1193.

4. Nam YD, Chan HW, Kim KH, Roh SW, Kim MS, Jung MJ et al. 2008. Bacterial, archaeal and eurkaryal diversity in the intestines of korean people. J Microbiol 46:491501.

5. Breitbart M, et al. 2003. Metagenomic analysis of uncultured viral community from human feces. J Bacteriol 185:6220-6223.

6. Kunz C, Kuntz S, Rudloff S. 2009. Intestinal flora. Adv Exp Med Biol 639:67-79.

7. Whitman WB, Coleman DC, Wiebe WJ. 1998. Prokaryotes: the unseen majority. Proc Natl Acad Sci USA 95:6578-6583.

8. Freestone P, Sandrini S, Haigh R, Lyte M. 2008. Microbial endocrinology: how stress influences susceptibility to infection. Trends Microbiol 16:55-64.

9. Breitbart M, Miyake J, Rowher F. 2004. Global distribution of nearly identical phage-encoded DNA sequences. FEMS Microbiol 236:249-256.

10. Pausz C, Clasen J, Suttle C. 2009. Isolation Independent Methods of Characterizing Phage Communities In: Bacteriophages: Methods and Protocols. Humana Press pp 255-269
11. DeLong EF. 1992. Archaea in coastal marine environments. Proc Natl Acad Sci USA 89:5685-5689.

12. Coolen MJ, Hopmans EC, Rijpstra WC, Muyzer G, Schouten S, Damste D. 2004. Evolution of methane cycle in ace lake (Antarctica) during the Holocene: response of methanogens and methanotrophs to environmental change. Org Geochem 35:1151-1167.

13. Vissers EW, Bodelier PLE, Muyzer G, Laanbrook HJ. 2009. A nested PCR approach for improved recovery of archaeal 16S rRNA gene fragments from freshwater samples. FEMS Microbiol Lett 298:193-198.

14. Smit E, Leeflang P, Glandorf B, van Elsas JD, WernarsK. 1999. Analysis of the fungal diversity in the wheat rhizosphere by sequencing of cloned PCRamplified genes encoding $18 \mathrm{~S}$ rRNA and temperature gradient gel electrophoresis. Appl Environ Microbiol 65:2614-2621.

15. Vainio EJ, Hantula J. 2000. Direct analysis of woodinhabiting fungi using denaturing gradient gel electrophoresis of amplified ribosomal DNA. Mycol Res 104:927-936.

16. Costa R, Götz M, Mrotzek, N, Lottmann, J, Berg, G, Smalla, K. 2005. Effects of site and plant species on rhizosphere community structure as revealed by molecular analysis of microbial guilds. FEMS Microbiol Ecol 56:236-249. 